\title{
Interseccionalidade de raça e gênero nas escolas brasileiras e os projetos de lei silenciadores
}

\author{
Intersectionality of race and gender in Brazilian schools and the bills silencers
}

Interseccionalidad de raza y género en las escuelas brasileñas y los proyectos de ley silenciadores

\author{
SASKYA MIRANDA LOPES ${ }^{1}$ \\ Universidade Estadul de SANTa CruZ, UESC, IlHÉus-BA, Brasil
}

\begin{abstract}
RESUMO
Na última década o governo brasileiro impulsionou políticas públicas e a construção de um conjunto de leis quanto aos direitos humanos e a educação em direitos humanos. Partindo da importância destas iniciativas, diante do colonialismo, racismo e patriarcado, que marcam a história de formação da sociedade brasileira, o presente ensaio se ancora em um referencial feminista descolonial e interseccional de raça, gênero e classe para descrever os avanços quanto à educação em direitos humanos, particularmente quanto aos direitos das mulheres, negras e negros e LGBTQ, no país. Ao mesmo tempo, denuncia as propostas legislativas que se disseminam atualmente pelo país e representam um retrocesso para a conquista da educação em direitos humanos.
\end{abstract}

Palavras-chave: Educação. Direitos Humanos. Gênero. Feminismo. Interseccionalidade.

\begin{abstract}
In the last decade, the Brazilian government has promoted public policies and the construction of a set of laws on human rights and human rights education. Based on the importance of these initiatives, in the face of colonialism, racism and patriarchy, which mark the history of the formation of Brazilian society, the present essay is anchored in a decolonial and intersectional feminist referential of race, gender and class to describe advances in human rights education, particularly regarding the rights of women, men and women black and LGBTQ, in the country. At the same time, denounce the legislative proposals that are currently disseminated throughout the country and they represent a setback for the achievement of human rights education.
\end{abstract}

Keywords: Education. Human Rights. Gender. Feminism. Intersectionality.

\section{RESUMEN}

En la última década el gobierno brasileño impulsó políticas públicas y la construcción de un conjunto de leyes en cuanto a los derechos humanos y la educación en derechos humanos. El presente ensayo se ancla en un referencial feminista descolonial e interseccional de raza, género y clase para describir los avances en cuanto a la educación en la educación en la educación derechos humanos, particularmente en cuanto a los derechos de las mujeres, negras y negros y LGBTQ, en el país. Al mismo tiempo, denuncia las propuestas legislativas que se diseminan actualmente por el país y representan un retroceso para la conquista de la educación en derechos humanos.

Palabras clave: Educación. Derechos Humanos. Género. Feminismo. Interseccionalidad.

\footnotetext{
${ }^{1}$ Professora Assistente do Departamento de Ciências Jurídicas da UESC. E-mail: profsaskya@gmail.com
} 


\section{INTRODUÇÃO}

O presente ensaio pretende provocar uma reflexão sobre a importância da abordagem interseccional no aprofundamento da compreensão das sobreposições de opressões, particularmente de raça e gênero dentro do contexto brasileiro, enquanto país marcado pela colonialidade, racismo e patriarcado. Também tem como intenção destacar a relevância das conquistas em educação para os direitos humanos de gênero e raça/etnia nos últimos treze anos no Brasil, com previsão legal destes temas no sistema educacional brasileiro e denunciar o atual movimento no cenário político legislativo do país contrário a este debate.

Desta forma o texto está dividido em cinco partes: na primeira parte exponho brevemente alguns dos principais conceitos para o feminismo. Na segunda parte trago as discussões atinentes à interseccionalidade, particularmente a discussão de raça, gênero e classe em outros países e no Brasil. Na terceira parte abordo a constituição dos direitos humanos como instrumento ambíguo na luta por igualdade racial e de gênero, ao mesmo tempo, aponto as brechas legais criadas para inserir este debate no sistema educacional brasileiro, através da legislação que inclui o estudo sobre direitos humanos e diversidade nos currículos escolares. Na quarta parte apresento o cenário e as perspectivas de retrocesso legal quanto a esta conquista, face aos projetos de lei que vedam a discussão sobre gênero surgido em vários estados brasileiros. A quinta parte, figura a título de conclusão com a indicação dos prejuízos como a perpetuação da cultura do racismo e da violência para meninas e jovens, particularmente as negras, por conta da ausência desse investimento qualificado na educação em direitos humanos de gênero e raça.

\section{GÊNERO E PATRIARCADO}

Atualmente muitas autoras feministas acreditam não mais ser necessário insistir nas distinções entre sexo e gênero, após o intenso trabalho das feministas da década de 1970 ou segunda onda do feminismo, especificamente para desconstruir as fundamentações biológicas da inferioridade da mulher diante dos homens, que justificavam a necessária submissão desta a este. Contudo, o século XXI tem sido assombrado por uma onda de conservadorismo, de fundamentalismos religiosos, materializado em violências físicas e psicológicas, em discursos de ódio, em intolerância às diferenças, culminando com alguns retrocessos em direitos humanos e aqui faço referência ao Brasil, que nos obriga a retornar às fundamentações das distinções entre sexo e gênero.

As diferenças concebidas historicamente a partir da distinção dos órgãos genitais, a partir dos quais se define o sexo masculino e feminino, antes aparentemente imutável revelou-se submetida à outra variável menos tangível, que se revela aos indivíduos no reconhecimento de suas subjetividades, nas experiências criativas de sua identidade e expressão do ser, o gênero.

Segundo Facio e Fries (2005) e Piscitelli (2009) os estudos de casos de crianças que tiveram a atribuição de sexo ao qual não pertenciam geneticamente, por nascerem com formação da genitália incompleta, ou intersexuais foram largo objeto de pesquisa depois de um dos casos mais conhecidos, do psiquiatra Robert Stoller, que aconselha a socialização de um garoto como garota após uma cirurgia de circuncisão mal sucedida em que a criança perde o pênis, e isto o induz a refletir que nem sempre a identidade sexual é determinada pelo sexo biológico. Continuando suas pesquisas, estudou outras centenas de casos semelhantes e influenciou o movimento feminista com a publicação 
do livro Sexo e Gênero, em 1968, onde defende que gênero se refere à imagem, aos pensamentos e à conduta de um sexo ou outro e isto não tem base biológica.

A partir de outros estudos e publicações neste mesmo sentido, as feministas da década de 1970 se apropriam destas pesquisas sobre a distinção de sexo e gênero para desconstruir a justificativa de uma inferioridade natural da mulher em relação ao homem, visto que estes papéis de homem e de mulher eram construções sociais, iniciadas antes mesmo do nascimento, sobre os comportamentos esperados para meninas e meninos. Quanto mais os estudos se aprofundam mostram que os padrões esperados de homem na América Latina podem ser diferentes dos esperados de um homem asiático e que nenhum deles corresponderá cem por cento a este padrão. Pois nesta construção de identidade de gênero ainda se deve incluir raça, etnia, geração, deficiências, nacionalidade... Para Facio e Fries (2005, p. 271) gênero é: “[...] um conjunto de características e comportamentos, como os papéis, funções e classificações impostas dicotomicamente a cada sexo através do processo de socialização, mantidos e reforçados pela ideologia e instituições patriarcais".

Desta forma o sistema de sexo-gênero ao atribuir atitudes, características e expectativas de maior valor e prestígio aos homens, do que às mulheres, demonstram razões ideológicas e políticas de hierarquização diametralmente opostas entre os sexos, fato denunciado pelas teorias feministas. Autoras como Saffioti (2009) evitam o movimento de sair de um essencialismo biológico para cair num essencialismo cultural, defendendo esta construção como conjugação de fatores bio-psico-sociais, pois o sexo pode ser redesignado a partir do gênero e o gênero pode ser ressignificado independente do sexo.

O mais importante é perceber como o conceito de gênero pôs em evidência a estrutura patriarcal da sociedade, a forma de construção política e ideológica de dominação e exploração da mulher em vários níveis. A razão cartesiana constitutiva da racionalidade moderna, denominada por Santos (2002) de razão indolente, consiste exatamente em uma dicotomia totalizante que esconde uma hierarquia entre as partes deste todo, onde cada parte só existe em relação à outra, homem e mulher, negros e brancos, primitivo e civilizado, esta estrutura do pensamento ocidental está em tudo e fundamenta a dominação-exploração de uma parte sobre a outra seja pelo patriarcado, pelo colonialismo ou capitalismo.

Facio e Frieso (2005) elencam cinco características comuns aos sistemas patriarcais: 1- é um sistema de origem histórica e não natural, antes da predominância do patriarcado existiram sociedades matriarcais; 2- estabelece a dominação pela força da violência sexual sobre a mulher, através da sujeição e controle do corpo e da reprodução feminina, de forma institucionalizada com a família e o Estado; 3- a mulher estará subordinada às opressões de um homem, independente da categoria social, econômica ou cultural deste; 4- justifica a manutenção da submissão da mulher ao homem por diferenças biológicas; 5- os mecanismos de manutenção e reforço do patriarcado ocorrem por diversas instituições e institutos que diminuem ou invisibilizam a mulher: a linguagem, a educação androcêntrica, a história roubada, a maternidade forçada, a família patriarcal, as religiões misóginas, a heterossexualidade forçada etc.

A partir do enfrentamento ao patriarcado foram estabelecidas outras bases de luta para o feminismo das décadas de 1970 em diante, Castells (1996, p. 10) então o definirá como:

[...] aquelas pessoas e grupos, reflexões e atuações orientadas a acabar com a subordinação, desigualdade e opressão das mulheres e lograr, portanto, sua emancipação e a construção de uma sociedade em que já não caiba as discriminações por razão de gênero e sexo. 
Passando a questionar todas as estruturas e ideologias que colocam o homem como central e superior sob diferentes perspectivas, nasceram diversas correntes do feminismo, mas segundo Facio e Fries (2005) mantendo em comum: a- a crença na igualdade de valor dos seres humanos, igualmente diferentes e igualmente semelhantes. Mesmo com as especificidades de raça, sexo etc. as diferenças não podem ser entendidas como inferioridade; b- toda forma de opressão e discriminação são rechaçadas, pois se retroalimentam; c- o feminismo põe a harmonia e felicidade do ser humano como mais importante que a produção, a acumulação de riqueza, o poder e a propriedade; d- para o feminismo o pessoal é público, indo de encontro à ideologia patriarcal dicotômica ao dividir as esferas da vida entre público e privado, prestigiando o espaço público e atribuindo-o ao homem e conferindo menos valia ao espaço privado, pertencente à mulher. Espaço invisibilizado onde as violências se perpetuam e de onde é esperado o silêncio; e- uma das pretensões da submissão patriarcal é o disciplinamento e controle do corpo feminino através do direito, da religião, da medicina - o Estado e a sociedade institucionalizam e legitimam esse controle; f- o feminismo reconhece gênero como uma categoria social perpassada por tantas outras como raça, etnia, classe, sexualidade e geração.

\section{AS INTERSECCIONALIDADES}

Uma grande mudança ocorreu nas décadas de 1980 e 1990 dentro do feminismo, pois mulheres não brancas começaram a questionar os modelos unitários de gênero forjados pelas mulheres, em sua maioria branca de classe média, da década de 1960 e 1970. Em crítica ao livro símbolo do feminismo da primeira onda, Mística feminina de Friedan, sobre a condição de mulheres brancas instruídas, que se tornaram donas de casa nos Estados Unidos por conta do patriarcado, Hooks (2015) destaca que neste mesmo período mais de um terço de todas as mulheres trabalhavam. Hooks afirma que a estrutura de classe nos Estados Unidos foi moldada por uma estratégia racial de dominação e exploração branca, dialogando com Quijano (2005) quando este aponta a centralidade da questão racial para a construção do capitalismo nas Américas, como a outra face da moeda colonial na modernidade, forjaram-se as teorias racializadoras para legitimar a inferioridade natural de negros e indígenas, facilitando assim a aceitação da exploração escravista da mão de obra destes povos no novo continente e o seu genocídio.

Contudo, as adaptações constantes do capitalismo às mudanças sociais conduziram à conclusão de que "Ser oprimida, significa ausências de opções" (HOOKS, 2015, p. 197). A autora demonstra como no capitalismo o patriarcado se estrutura para o sexismo deixar uma margem de liberdade em relação às restrições impostas, conduzindo algumas mulheres a acreditarem que não sofrem opressões. Assim, entende que o movimento feminista por oportunidade igual de trabalho e ganhos individuais de mulheres da classe média, que pretendiam igualdades com homens da mesma classe, prejudicou a luta coletiva e facilitou a cooptação de muitas pelo capitalismo liberal individualista. Então Hooks reclama por um feminismo sob perspectiva diferente, considerando que as feministas brancas não são capazes de falar por outros grupos de mulheres, conclama as mulheres negras a assumirem esse papel, pois carregam o fardo do machismo, racismo e classismo.

Passou-se a exigir do feminismo uma análise do que é ser mulher considerando-se classe, raça e sexualidade. Caldwell (2000) descreve então como estas mulheres negras, indígenas, não brancas americanas, negras inglesas, e feministas do chamado terceiro 
mundo deram contribuições significativas neste sentido. Percebeu-se a importância de entender os modos pelos quais se define o "ser mulher" em relação a mulheres de outras raças, etnias, classes, a importância de se delimitar uma análise local de gênero, perceber as especificidades sociais, culturais e históricas. Nos Estados Unidos e na Inglaterra os impactos da nova onda feminista foram maiores na década de 1990, quando os debates sobre a desessencialização da questão de gênero e as identidades conduziram a uma discussão sobre o papel da "diferença" na teoria feminista.

Em virtude desta reflexão levantada pela terceira onda Caldwell (2000) faz duras críticas à demora das feministas brasileiras tratarem as diferenças, com ressalva para Lélia Gonzales, Sandra Azerêdo, Sueli Carneiro e Luiza Bairros que enegrecem o feminismo brasileiro, tratando da intersecção de raça, gênero e classe, da situação das empregadas domésticas como um legado da escravidão, entre as diferenças e privilégios das mulheres brancas em relação às mulheres negras e a indissociabilidade da questão de classe e raça para estas no país.

A autora defende como fundamental para entender a heterogeneidade dentro da população feminina brasileira, perceber as diferenças na experiência de vida entre mulheres brancas e mulheres negras. $O$ gênero perpassa e é perpassada por raça, etnia, classe social, orientação sexual, faixa etária e torna evidentes as diferentes formas de opressão vivenciada por uma mulher branca, heterossexual, jovem, de classe alta e as de uma mulher, negra, pobre, lésbica e idosa. Por mais que ambas sofram a mesma pressão patriarcal de submissão, de inferiorização pelo machismo, invisibilizadas pela linguagem, marginalizadas pela história, uma enfrentará uma carga mais diversa e pesada de violências do que a outra. Sob esta perspectiva o termo interseccionalidade é cunhado por Crenshaw (2002, p. 177) para tratar da chamada:

[...] associação de sistemas múltiplos de subordinação tem sido descrita de vários modos: discriminação composta, cargas múltiplas, ou como dupla ou tripla discriminação. A interseccionalidade é uma conceituação do problema que busca capturar as conseqüências estruturais e dinâmicas da interação entre dois ou mais eixos da subordinação. Ela trata especificamente da forma pela qual o racismo, o patriarcalismo, a opressão de classe e outros sistemas discriminatórios criam desigualdades básicas que estruturam as posições relativas de mulheres, raças, etnias, classes e outras. Além disso, a interseccionalidade trata da forma como ações e políticas específicas geram opressões que fluem ao longo de tais eixos, constituindo aspectos dinâmicos ou ativos do desempoderamento.

A abordagem da discriminação racial a partir do gênero destaca as diferenças do abuso e violações de direitos humanos que as mulheres passam e os homens não. Contudo Crenshaw (2002) destaca a dificuldade deste tipo de análise ao incorrer em abordagens superinclusivas ou subinclusivas: superinclusivas quando os outros aspectos interseccionais como raça ou classe são absorvidos pela análise de gênero e a subinclusão, muito comum na discussão racial quando reúne homens e mulheres, onde algumas violências são sofridas por todos, mas outras são experimentadas exclusivamente ou prioritariamente pelas mulheres. É o caso das depreciações quanto à estética da mulher negra, o cabelo, os traços físicos, levando movimentos sociais a trabalharem a valorização da imagem e autoestima da mulher negra no Brasil. Resumindo, na subinclusão a diferença se torna invisível um conjunto de problemas e na superinclusão a própria diferença é invisível.

Com outras nuances, Collins (2000) usa o conceito de matriz de dominação para pensar a interseccionalidade das desigualdades, onde uma pessoa pode se encontrar em diferentes posições, a depender de suas características. E as diferentes formas de ser 
mulher estariam nestas intersecções entre gênero, raça, classe, geração, sem predominância de algum elemento sobre outro. Em cada lugar, um ou alguns destes elementos são acionados de acordo com as circunstâncias. Neste mesmo sentido Audre Lorde (2012) é incisiva ao afirmar que "não há hierarquia de opressões", “[...] dentro da comunidade lésbica eu sou negra, dentro da comunidade negra eu sou lésbica" (p. 5), as opressões se cruzam, se sobrepõem, se chocam e só o desenvolvimento de uma análise detalhada das perspectivas variantes podem desenvolver intervenções de efeitos mais eficazes.

\section{DIREITOS HUMANOS: GÊNERO E EDUCAÇÃO}

Instrumentos legais importantes são formulados para a consolidação dos direitos humanos na América Latina e no mundo, tais como: a Convenção Americana de Direitos Humanos, conhecida como Pacto de São José da Costa Rica em 1969, mas que só foi promulgado no Brasil em 1992; a I Conferência Mundial sobre a Mulher realizada na Cidade do México em 1975; a Convenção Para Eliminar Todas as Formas de Discriminação Contra a Mulher - CEDAW, de 1979, ratificada pelo Brasil com ressalvas em 1984, que só foram vetadas dez anos depois; a II e III Conferência Mundial sobre a Mulher, realizadas em Copenhague (1980) e em Nairóbi (1985), onde se avaliou e elaborou estratégias sobre o progresso dos direitos das mulheres; a Convenção de Belém do Pará (Convenção Interamericana para Prevenir, Punir e Erradicar a Violência Contra a Mulher - 1994) onde se definiu todas as formas de violência contra a mulher; a IV Conferência Mundial sobre a Mulher em Beijing (1995), onde foi estabelecida uma nova agenda de reivindicações e se exigiu o cumprimento dos compromissos assumidos em tratados e convenções anteriores através de políticas públicas (especialmente para as americanas); a III Conferência Mundial contra o Racismo, a Discriminação Racial, a Xenofobia e formas Conexas de Intolerância (conhecida como Conferência de Durban - 2001), onde se reafirmou a discriminação racial e toda forma de intolerância como uma afronta aos Direitos Humanos, estabelecendo a necessidade de contemplar esta questão sob a perspectiva de gênero; a Convenção e Recomendação da OIT sobre Trabalho Decente para as Trabalhadoras e os Trabalhadores Domésticos, em Genebra - 2011, onde se assegurou proteção e equiparação de direitos entre trabalhadoras domésticas e demais.

Nesse cenário, o Brasil cede às discussões, avanços sobre direitos humanos, contudo, sob a pressão externa da globalização capitalista, um colonialismo moderno, onde o discurso dos direitos humanos foi absorvido como gramática de um Estado democrático de direito e inserido no contexto da globalização. Entretanto, contendo em si a armadilha da universalização homogeneizadora dos contextos mais diversos a um único modelo imposto como o melhor a ser seguido, independente das realidades da América Latina, África e Ásia, tão diferentes entre si, e da Europa. Mas estas formas diversas de entender o mundo são consideradas inferiores, improdutivas, obsoletas, provincianas, ou ignorantes, segundo a única racionalidade permitida de se vivenciar a existência: a racionalidade moderna eurocêntrica, que divide o mundo (por uma linha abissal) em norte e sul global e onde esse norte determina o válido, o legítimo e o justo (SANTOS, 2007).

A Declaração Universal dos Direitos Humanos foi criada para universalizar garantias independentemente de sexo, raça, etnia, mas durante muito tempo e ainda hoje, em alguns lugares esta igualdade é apenas formal, pois as violações contra as mulheres dentro de um sistema patriarcal não são vistas como violações de direitos humanos (CRENSHAW, 2002). Muita coisa foi se ajustando ao longo do tempo, por 
reivindicações e lutas dos não contemplados, por isso, não se trata de negar o papel dos direitos humanos como uma linguagem em defesa da dignidade humana, mas enfatizar a questão levantada por Santos (2015): Como um direito construído a partir das epistemologias do Norte, capitalistas, coloniais e patriarcais, legitimadora desta forma de perceber o mundo, poderá promover a dignidade dos excluídos?

A lei e o direito tem um suposto sentido histórico revolucionário para o lado Norte da linha (revolução francesa, americana) e serviram bem ao individualismo burguês e às teorias liberais, coloniais e capitalistas, reproduzindo dominação, exclusão, opressão e exploração ao Sul desta linha abissal.

Os direitos humanos tornaram-se hegemônicos, porque foram entendidos segundo a racionalidade moderna monocultural e linear, onde o sentido dos seus interesses é sinônimo de progresso como resultado lógico de uma sociedade justa. Transformaramse em ideologia política, em uma missão civilizatória e sagrada do capitalismo neoliberal, tornando-se monopólio do Estado, único responsável pelas leis e aplicação da justiça.

Essa combinação entre direitos humanos e capitalismo neoliberal foi possível porque as normas civis e a moral global são necessárias para um capitalismo neoliberal mundial. Santos (2015) afirma que gradualmente a dignidade humana defendida pelos direitos humanos se moldou às políticas liberais, às mudanças do capitalismo e ao colonialismo moderno. Em relação ao sexismo, houve um avanço seletivo para os direitos trabalhistas femininos, onde a mulher branca ocupa um lugar privilegiado enquanto a mulher negra é subvalorizada há séculos. Assim, os direitos civis e políticos individuais liberais, surgem como o nível mais baixo de garantia de inclusão e cidadania para alguns.

Desta forma os negros, mulheres, indígenas, imigrantes, o povo colonizado ou escravizado, os habitantes abaixo da linha abissal terão acesso efetivo aos direitos humanos? As marcas da colonização continuam na modernidade a determinar os privilégios legalmente garantidos aos homens brancos heterossexuais, ainda que os direitos humanos sejam nomeados de universais.

Ao fim, a Declaração não deu visibilidade às exclusões do outro lado da linha abissal, pois o racismo e o sexismo faziam parte da normalidade do entendimento hegemônico. Os direitos humanos não foram feitos para os grupos excluídos, segundo Douzinas (2011, p. 10), estes grupos: “[...] têm sido radicalmente excluídos da ordem social, eles são invisíveis, [...]. Políticas adequadas surgem apenas quando uma parte excluída demanda ser inclusa e deve mudar as regras de inclusão para conseguir isto".

E as lutas e demandas pelo mundo ao longo da história conduziram as vitórias e reconhecimento destes sujeitos excluídos, momento em que a tensão ocorre, pois o sucesso desta demanda coletiva faz nascer um novo sujeito político, parecendo um excesso para o grupo estabelecido e visível. É o que ocorre, por exemplo, com as políticas afirmativas e reparatórias sobre o racismo no Brasil ou a ampla discussão sobre o patriarcado, que legitima o machismo e a violência contra a mulher. Assim, no campo dos direitos humanos é reiterada a hegemonia liberal, mas também existem lacunas reveladoras das opressões, exclusões. As lutas e reivindicações pela realização de direitos humanos dos grupos excluídos, discriminados destacam os conflitos políticos e sociais invisibilizados. Contudo, Crenshaw (2002) alerta que a ampliação das garantias de direitos humanos de gênero só alcançará efetividade à medida que se intersectar com outras identidades que vulnerabilizam determinado grupo de mulheres.

Foi assim que nos últimos treze anos de um governo progressista no Brasil, com a instituição de um Ministério de Políticas para as Mulheres e outro Ministério de Promoção da Igualdade Racial, muitas inciativas, experiências e oportunidades foram 
construídas para promover a luta contra o machismo e o racismo dentro da sociedade brasileira. Foram realizadas bienalmente três Conferências Municipais, Estaduais e Nacionais de Mulheres, a partir das quais foi forjado o Plano Nacional de Políticas para mulheres, traçando diretrizes das políticas públicas para mulheres, a partir das demandas amplamente discutidas pela sociedade nestes eventos que reuniram representações de todo país. Também foram publicados editais de financiamento para promoção de projetos culturais e educacionais; campanhas institucionais de enfrentamento à violência doméstica contra a mulher; promoção de canais de denúncia diretos, como o disque 100; reconhecimento do papel estratégico da mulher como chefe de família ao entregar as casas de projeto popular, como o "Minha casa, minha vida" em nome da esposa e não do marido; campanhas de saúde, prevenção e enfrentamento a câncer específicos do público feminino.

Nesta mesma esteira foram realizadas as três Conferências Nacionais de Promoção da Igualdade Racial, composta por participantes eleitos nas Conferências Estaduais e Municipais, com elaboração de políticas públicas de enfrentamento ao racismo, à objetificação da mulher negra, com o fomento à construção de um arcabouço legislativo de proteção e promoção da identidade negra brasileira, desde a exigência de presença de pessoas negras em peças publicitárias até o Estatuto da Igualdade Racial, perpassando pelas políticas públicas de cotas para ingresso em Universidades e editais para financiamento de projetos que promovessem a cultura afrobrasileira, a educação para a igualdade, o enfrentamento ao racismo e à intolerância a religiões afrobrasileiras.

Estas ações foram reforçadas por políticas de promoção dos direitos humanos, desde a existência de uma Secretaria de Direitos Humanos, até a promulgação de leis instituindo o Plano Nacional de Educação em Direitos Humanos e a Resolução que estabelece as Diretrizes Nacionais para a Educação em Direitos Humanos em todos os níveis da educação.

A educação em direitos humanos, particularmente de gênero e raça, impõe-se como consenso e prioridade, ao ser reconhecida como uma das formas mais eficazes de mudança social e enfrentamento às diversas violências e opressões geradas e sobrepostas pelos preconceitos contra a mulher, homossexuais, transexuais e negros.

A sinalização para a necessidade de uma educação humanista, não discriminatória e que transversalmente contemple os direitos humanos, está presente desde a Constituição da República (BRASIL, 1988), passando pela Lei de Diretrizes e Bases da Educação - LDB (BRASIL, 1996) e o Plano Nacional de Educação (BRASIL, 2014) que estabelece a erradicação de toda forma de discriminação, mesmo expressamente não determinando a discussão de gênero, também não a proíbe.

Nestes documentos é reiterada a defesa da própria educação como direito humano e constitucional, de um ensino de qualidade que valorize a dignidade humana, a igualdade de direitos, o reconhecimento e valorização da diversidade e da diferença, a transversalidade na abordagem dos temas de direitos humanos e a formação continuada para aperfeiçoamento dos professores sobre a temática, conforme o artigo $3^{\circ}$ das Diretrizes Nacionais para a Educação em Direitos Humanos (BRASIL, 2012).

O Estado brasileiro ainda assume compromisso com o Programa Mundial de Educação em Direitos Humanos no seu Programa Nacional em Educação em Direitos Humanos (BRASIL, 2014) e reconhece a educação como um processo sistemático e multidimensional que fomenta a formação de sujeitos para:

[...] exercitar o respeito, a tolerância, a promoção e a valorização das diversidades (étnico-racial, religiosa, cultural, geracional, territorial, físicoindividual, de gênero, de orientação sexual, de nacionalidade, de opção 
política, dentre outras) e a solidariedade entre povos e nações (BRASIL, 2014, p. 25).

A LDB garante a educação básica obrigatória e gratuita, dos quatro aos dezessete anos de idade e em várias partes está expressa a obrigatoriedade dos currículos contemplarem a discussão das realidades sociais e políticas brasileiras (Art. 26, $\S 1^{\circ}$ ) e dos valores fundamentais aos interesses sociais (Art. 27, I) (BRASIL, 1996).

Estas discussões são indispensáveis, pois nas escolas as meninas são controladas, depreciadas e condicionadas a determinados comportamentos por serem meninas, meninas negras sofrem violências psicológicas e morais, humilhações e constrangimentos por sua cor, seus cabelos, por seus traços físicos. É no espaço escolar que se reforçam os estereótipos dos papéis de gênero masculino e feminino, ainda fundamentado nas justificativas biológicas, onde 38,2\% das atitudes discriminatórias por gênero ocorrem, seguidas das atitudes discriminatórias por orientação sexual, com 26,1\% (HAJE, 2015). Mas é também nas escolas, através de debates, apresentações teatrais, musicais, poéticas ou trabalhos de pesquisa que as garotas podem expressar sua raiva pelas opressões patriarcais, como afirma Hooks (2015), e confrontar a realidade em um espaço seguro de discussão orientada por docentes.

Os professores, estudantes, pais, amigos da escola e movimentos sociais precisam utilizar as ferramentas disponíveis para atuar solidariamente, unirem-se nos pontos de interseccionalidade entre eles, seja pela cor, por ser mulher ou ser pobre, traduzir os discursos de cada um dentro desta diversidade, e para garantir essa diversidade, pois a conjuntura política pós-eleições parlamentares de 2014 se tem revelado perigosa para os direitos conquistados.

\section{A TENTATIVA DE SILENCIAMENTO}

A obrigatoriedade do estudo sobre direitos humanos, em particular de gênero e raça, entra na agenda política brasileira e nos currículos escolares por força do ativismo dos movimentos sociais e das pressões externas diante dos altos índices estatísticos de morte e violência, majoritariamente sobre as mulheres negras. Entre os anos de 2003 e 2013, houve um incremento de $21 \%$ no homicídio de mulheres no Brasil, considerando o aumento da população feminina na década, ainda assim houve um aumento de $11,1 \%$. Dentre estas mortes, o homicídio das mulheres negras cresceu $54 \%$, enquanto o de mulheres brancas caiu 9,8\% (WAISELFISZ, 2015).

Apesar da violência doméstica, do feminicídio, a luta contra o patriarcado e o racismo não é aceita com parcimônia pela parte conservadora da sociedade brasileira, cada vez mais representada politicamente nos parlamentos nacionais, estaduais e nas câmaras de vereadores das cidades brasileiras. E este segmento político e religioso passa a evocar os essencialismos biológicos, os fundamentos das religiões judaico-cristãs, particularmente a vertente neopentecostal, referente à submissão da mulher ao homem, sua obrigação de obediência ao mesmo, de serviço à família e a Deus. Ao mesmo tempo demoniza o conceito de gênero, o associa exclusivamente às questões de orientação sexual, sendo fortemente atacada e rechaçada qualquer possibilidade de direito aos LGBTQ.

Contrariando as legislações existentes para a Educação em Direitos Humanos e as conquistas dos movimentos sociais: feminista e negro (avanço no reconhecimento dos direitos das mulheres, do enfrentamento às desigualdades sobrepostas à mulher negra e homossexual, às violências diversas promovidas pelo machismo e o patriarcado), instalou-se em pelo menos metade dos estados brasileiros, por diversas câmaras municipais e algumas assembleias estaduais a votação de projetos de lei que visam 
proibir professores de discutirem gênero em sala de aula, sob pena de demissão e até prisão.

Até o meio do ano de 2016 tramitaram conjuntamente no Congresso Nacional pelo menos 5 projetos de lei que visam interferir nos conteúdos curriculares, desde incluir no Plano Nacional de Educação a proibição de discussões sobre gênero nas escolas (PL 2731/2015), assim como o PL 1859/2015, que pretende alterar a Lei de Diretrizes e Bases para proibir educação sexual e adoção de "ideologia de gênero nas escolas", ou o PL 7180/2014, que também pretende alterar a LDB para dar prioridade às convicções morais, sexuais e religiosas dos pais sobre a educação escolar dos filhos e o PL 5487/2016 que visa a proibição da distribuição de livros sobre orientação sexual nas escolas pelo Ministério da Educação. Sem dúvidas, o mais punitivo é o PL 2731/2015, pois prevê a prisão de 6 meses a 2 anos para os professores que desrespeitarem a lei, contudo o mais completo é o PL 867/2015, que pretende a alteração da LDB para incluir o programa Escola sem partido, onde reúne todas as pretensões já elencadas nas demais propostas, como a vedação de práticas de doutrinação política e ideológicas contrárias às convicções dos pais e a exigência de autorização expressa dos mesmos para ministrar temas que vão de encontro a seus posicionamentos.

Este tipo de lei, além de vetar o desenvolvimento de uma educação crítica, interfere na liberdade de cátedra dos professores, como aponta a professora Lisete Arelalo:

[...] liberdade de aprender, ensinar, pesquisar e divulgar o pensamento, a arte e o saber, bem como o pluralismo de ideias e concepções pedagógicas [...] Por que esta definição é importante? Porque ela traduz o dever e a responsabilidade da professora ministrar suas aulas a partir de suas convicções pedagógicas e da sua visão de mundo. Essas convicções se expressam a todo o momento: a indicação da leitura de um livro ou artigo, a apreciação de uma obra de arte, a discussão dos valores democráticos desenvolvidos nas suas aulas, o respeito aos direitos humanos que o cotidiano escolar expressa e exige (ZINET, 2016).

Além disso, o PL 867/2015 está construído com termos vagos, imprecisos e de difícil subsunção dos tipos legais à prática, por exemplo, quem decide se há ou não doutrinação? Quem definirá e com quais critérios o que é ideológica? Ou política? Uma norma legal e, particularmente, uma norma incriminadora, deve respeitar o princípio da legalidade, da expressão clara e taxativa, ser objetiva o máximo possível.

Esta grande quantidade de projetos de lei tem iniciativa de legisladores que afirmam estar defendendo a "família tradicional", cunhando e disseminando a ideia de que os professores promovem doutrinações ideológicas sobre os alunos e, valendo de uma audiência cativa, usam o termo "ideologia de gênero" como forma pejorativa de referir-se aos estudos e debates sobre gênero e afirmam existir uma "doutrinação de gênero" para aceitação de uma "ditadura gay".

Como afirma o professor Fernando Penna:

Essa concepção completamente equivocada entra em contradição com toda a produção acadêmica do campo de pesquisa educacional, no qual se reafirma, de diferentes maneiras, que o aluno não é uma folha em branco na qual o professor pode imprimir o que bem lhe convém; o conhecimento escolar é produzido no diálogo entre professores e alunos e a sala de aula é o espaço pelo qual perpassam todas as vozes da nossa sociedade, trazidas por um conjunto extremamente heterogêneo de alunos, professores e funcionários (ZINET, 2016). 
A educação prevista pela legislação brasileira para o fortalecimento da cidadania e participação democrática perpassa desde a proteção da infância e juventude, em sua dignidade, integridade física e psicológica, como a formação crítica, autônoma e vasta para entender a realidade social na qual estão inseridos. Consequentemente, educar para gênero, sem esquecer sua interseccionalidade de raça e classe, conduz à transversalidade na educação étnico-racial, de gênero, de análise de conjunturas sociais que são realidades históricas, territoriais, geográficas, linguísticas, corporais, filosóficas, antropológicas, políticas, religiosas, pois o sujeito é composto de muitas subjetividades e a escola faz parte desta descoberta desde a infância até a juventude.

Sob um olhar interseccional, a possível aprovação destes projetos de lei atingirá de formas diferentes, mulheres: negras, brancas, lésbicas, gays, trans ou heteros, classe média ou pobre, pois a manutenção da supremacia patriarcal retroalimenta o racismo estruturante e a exploração capitalista. Por mais difícil que seja a efetividade das leis que combatem o sexismo e racismo, elas ainda são as brechas e ferramentas para os movimentos sociais contra hegemônicos, antirracistas, feministas, LGBTQ construírem suas lutas, de suas casas às ruas, das ruas às salas de aulas, por respeito e por direito a existir.

\section{CONSIDERAÇÕES FINAIS}

Todo movimento de retrocesso político de garantias sociais vivenciado no Brasil, desde as eleições de 2014, representa a resistência do patriarcado, do colonialismo branco e da elite capitalista, representa a opressão interseccional de gênero, raça e classe, face aos avanços sociais e da conquista de direitos promovidas nos últimos dez anos para mulheres, negros e pobres.

A tese da imbricação do capitalismo, colonialismo e patriarcado como formas de opressão conjuntas, defendida por Santos e Meneses (2009), torna-se visível quando relacionamos as consequências do enfrentamento de uma destas opressões e descuidamos das outras. Deixar de discutir o patriarcado como responsável pelo aprofundamento da diferença entre os gêneros é aumentar, como afirma Lagarde (1997, p. 291), “[...] a feminização da pobreza, a marginalização das mulheres, o feminicídios”, aumentando também a disputa patriarcal de um homem pelo outro, intensificando o machismo e a violência entre os homens, compreendida, dentro do sistema neoliberal e da racionalidade moderna, como a naturalização da exploração dos classificados como mais fracos, mais ignorantes e menos produtivos.

Deixar de enfrentar o sexismo, de entender e discutir a ideologia patriarcal e as verdadeiras causas que sustentam as diferenciações de gênero, é dar combustível ao fascismo social, a toda forma de preconceito ou fobia a pessoas diferentes, seja por qualquer uma das intersecções de opressões que se sobrepõe às de gênero, raça e classe, tais como posicionamento político, crença religiosa, nacionalidade ou orientação sexual.

Enfrentar e desconstruir as ideologias patriarcais racistas desde a infância, promovendo um espaço onde os professores recebam qualificação para discutir as experiências opressivas que ocorrem dentro e fora do espaço escolar, é levantar trincheiras entre humilhação e autoestima, submissão e resistência, silenciamento e ativismo, invisibilidade e identidade, entre a vida e a morte para muitas meninas, jovens e mulheres, mais contundentemente para as negras.

A construção de luta das mulheres negras, muito antes das mulheres brancas, pela sobrevivência diante da exploração como mão de obra escrava e depois mal remunerada em subempregos, pelos abusos sexuais e objetificação do corpo, o abandono da infância negra pelo poder público e a construção social da legitimidade do genocídio de uma 
juventude marginalizada desde o nascimento por sua cor da pele e criminalizada por seu status social, são exemplos de violências que vão do simbólico, moral, psicológico, ao físico e que acompanham as crianças desde sua infância, adolescência e juventude.

A compreensão da história de luta das mulheres por dignidade e direitos, do movimento negro feminino e LGBTQ, são mais que fatos históricos e políticos de lutas sociais que compõem a realidade brasileira, são exemplos de possibilidades diversas de vida, uma verdadeira ecologia de saberes, de enfrentamentos cotidianos das opressões para sobreviver - o Brasil possui a $5^{\mathrm{a}}$ maior taxa do mundo em feminicídios; a liderança mundial na morte de transexuais e travestis; as mulheres são remuneradas $30 \%$ a menos que os homens (2016a; 2016b).

Esta realidade desigual e violenta invade as salas de aulas nas histórias familiares de cada criança, na corporeidade e subjetividade de cada adolescente, de vários estudantes, na maioria negras e negros espalhados por todas as classes, mas em maior número nas periferias do Brasil.

É mais uma carga acrescida aos ombros dos professores, dentre outras cargas como a falta de reconhecimento, de condições de trabalho, às vezes, até de segurança. Além disso, a aprovação da retirada, dos Planos municipais e estaduais de educação, do termo gênero, impede o direcionamento de verbas para programas de qualificação destes profissionais para trabalhar com a educação de gênero em sua interface com a variante étnico-racial, o que se configura como um verdadeiro cerceamento das condições para capacitação.

Perpetuar a violência, a desigualdade e a injustiça, deixar de promover a desconstrução destas perspectivas machistas, sexistas, racistas e homofóbicas, é uma afronta ao Estado democrático de direito, é furtar o direito à educação do povo brasileiro. Aprovar projetos de leis que tentam silenciar a discussão crítica da história brasileira construída sob os pilares do patriarcado e do racismo, é por vezes condenar o garoto à prisão, a garota à morte, o jovem à criminalização e a jovem a uma vida de violências. Manter meninos na ignorância de uma lógica de violência machista e meninas nos falsos enredos do ciclo de violências simbólicas que minam suas forças através de violências morais e psicológicas nem percebidas, ou assistidas desde a infância dentro de suas casas, nunca questionadas, pois não foram discutidas, mas muitas vezes legitimadas por discursos sexistas e racistas, é tornar estas meninas números que fazem do Brasil um país assassino de mulheres, em sua maioria negra e pobre.

A educação étnico-racial no contexto brasileiro é indissociável de suas intersecções com classe e gênero, enquanto ferramenta indispensável para transformação social e construção de uma sociedade mais equânime. Esta afirmação pode ser consenso no campo formal, mas sua materialização é permeada por brigas no campo social, político e ideológico, assim, se aqueles que realmente precisam e se interessam pela mudança não se unirem, superando suas diferenças e aumentado a força de suas exigências, o direito a uma educação transversal em gênero, raça e classe, transformadora, crítica e emancipadora poderá ser realmente censurado.

\section{REFERÊNCIAS}

BRASIL. Plano Nacional da Educação: Lei no 13.005, de 25 de junho de 2014. Brasília: Casa Civil, 2014. Disponível em: < http://www.planalto.gov.br/ccivil_03/ato2011-2014/2014/lei/113005.htm >. Acesso em: 29 jun. 2018. 
BRASIL. Diretrizes Nacionais para a Educação em Direitos Humanos: resolução ${ }^{\circ} 1$, de 30 de maio de 2012. Brasília: CNE, 2012. Disponível em: < http://portal.mec.gov.br/dmdocuments/rcp001_12.pdf >. Acesso em: 29 jun. 2018.

BRASIL. Lei de Diretrizes e Bases da Educação Nacional: lei no 9.394, de 20 de dezembro de 1996. Brasília: Casa Civil, 1996. Disponível em: < http://www.planalto.gov.br/ccivil_03/LEIS/19394.htm >. Acesso em: 29 jun. 2018.

BRASIL. Constituição da República Federativa do Brasil. Brasília: Senado Federal, 1988.

CALDWELL, K. L. Fronteiras da diferença: raça e mulher no Brasil. Estudos Feministas, n. 2, p. 91$108,2000$.

CASTELLS, C. Perspectivas feministas em teoría política. Barcelona: Paidós, 1996.

COLLINS, P. H. Black feminist thought: knowledge, consciousness, and the politics of empowerment. 2. ed. New York: Routledge, 2000.

CRENSHAW, K. Documento para o encontro de especialistas em aspectos da discriminação racial relativos ao gênero. Revista Estudos Feministas, v. 10, n. 1, p. 171-188, 2002.

DOUZINAS, C. Os paradoxos dos direitos humanos. Anuário do Núcleo Interdisciplinar de Estudos e Pesquisas em Direitos Humanos da UFG, v. 1, n. 1, p. 1-15, 2011.

FACIO, A.; FRIES, L. Feminismo, género y patriarcado. Academia: Revista sobre Enseñanza del Derecho de Buenos Aires, v. 3, n. 6, p.259-294, 2005. Disponível em: < https://revistascolaboracion.juridicas.unam.mx/index.php/revista-ensenianza-derecho/article/viewFile/33861/30820 >. Acesso em: 29 jun. 2018.

HAJE, L. Educação debate aplicação da ideologia de gênero e orientação sexual no PNE. Câmara Notícias, Educação e Cultura, 10 nov. 2015. Disponível em: < http://www2.camara.leg.br/camaranoticias/noticias/EDUCACAO-E-CULTURA/499537-EDUCACAODEBATE-APLICACAO-DA-IDEOLOGIA-DE-GENERO-E-ORIENTACAO-SEXUAL-NO-PNE.html >. Acesso em: 29 jun. 2018.

HOOKS, B. Mulheres negras: moldando a teoria feminista. Revista Brasileira de Ciência Política, n. 16, p. 193-210, 2015.

LAGARDE, M. Identidad de género y derechos humanos: la construcción de las humanas. In: ILANUD. Instituto Latinoamericano de Naciones Unidas para la Prevención del Delito y Tratamiento del Delincuente. Caminando hacia la igualdad real: manual en módulos. San José: ILANUD/UNIFEM, 1997. p. 273-294. Disponível em: < https://dds.cepal.org/redesoc/portal/publicaciones/ficha/?id=1352 >. Acesso em: 29 jun. 2018.

LORDE, A. G. Não há hierarquias de opressão. In: LORDE, A. G. Textos Escolhidos de Audre Lorde. Heretica Difusao Lesbofeminista Independente, 2012. p. 5-6. Disponível em: < https://www.mpba.mp.br/sites/default/files/biblioteca/direitos-humanos/direitos-da-populacaolgbt/obras_digitalizadas/audre_lorde__textos_escolhidos_portu.pdf >. Acesso em: 29 jun. 2018.

ONU. Taxa de feminicídios no Brasil é quinta maior do mundo; diretrizes nacionais buscam solução. ONUBR, Nações Unidas no Brasil, 09 abr. 2016a. Disponível em: < https://nacoesunidas.org/onufeminicidio-brasil-quinto-maior-mundo-diretrizes-nacionais-buscam-solucao/ $>$. Acesso em: 29 jun. 2018.

ONU. Violência contra pessoas trans é 'extremamente alta' nas Américas, apontam ONU e parceiros. ONUBR, Nações Unidas no Brasil, 15 abr. 2016b. Disponível em: < https://nacoesunidas.org/violenciacontra-pessoas-trans-e-extremamente-alta-nas-americas-apontam-onu-e-parceiros/\# >. Acesso em: 29 jun. 2018. 
Saskya M. Lopes

PISCITELLI, A. Gênero: a história de um conceito. In: ALMEIDA, H.; SZWAKO, J. (Org.). Diferenças, igualdade. São Paulo: Berlendis \& Vertecchia, 2009. p.116-148.

QUIJANO, A. Colonialidade do poder, eurocentrismo e América Latina. In: LANDER, E. (Org.). A colonialidade do saber: eurocentrismo e ciências sociais. Perspectivas latino-americanas. Buenos Aires: CLACSO, 2005. $\quad$ p. 107-130. Disponível em: http://biblioteca.clacso.edu.ar/ar/libros/lander/pt/lander.html >. Acesso em: 29 jun. 2018.

SAFFIOTI, H. I. B. Ontogênese e filogênese do gênero: ordem patriarcal de gênero e a violência masculina contra mulheres. Brasília: FLACSO Brasil, 2009. (Série Estudos e Ensaios/Ciências Sociais). Disponível em: < http://flacso.redelivre.org.br/files/2015/03/Heleieth_Saffioti.pdf >. Acesso em: 29 jun. 2018.

SANTOS, B. S. If God were a human rights activist. Coimbra: Almedina/CES, 2015.

SANTOS, B. S.; MENESES, M. P. (Org.). Epistemologias do sul. Coimbra: Edições Almedina, 2009.

SANTOS, B. S. Beyond abyssal thinking: from global lines to ecologies of knowledges. Eurozine, 29 jun. 2007. Disponível em: < http://www.eurozine.com/articles/2007-06-29-santos-en.html >. Acesso em: 29 jun. 2018.

SANTOS, B. S. A crítica da razão indolente: contra o desperdício da experiência. São Paulo: Cortez, 2002.

WAISELFISZ, J. J. Mapa da violência 2015: homicídios de mulheres no Brasil. Brasília: Flacso Brasil, $2015 . \quad$ Disponível em: https://www.mapadaviolencia.org.br/pdf2015/MapaViolencia_2015_mulheres.pdf >. Acesso em: 29 jun. 2018.

ZINET, C. Projeto de lei prevê prisão de docente que falar sobre “ideologia de gênero". Geledés, Seção Questões de Gênero, 09 abr. 2016 Disponível em: < http://www.geledes.org.br/projeto-de-lei-preveprisao-de-docente-que-falar-sobre-ideologia-de-genero-2/ >. Acesso em: 29 jun. 2018.

Recebido em: 29 jun. 2018.

Aprovado em: 29 jul. 2018. 